\title{
The work-family balance of British working women during the COVID-19 pandemic
}

Royal Docks School of Business and Law, University of East London, London, UK

Opeoluwa Aiyenitaju

Department of Operations, Technology, Events and Hospitality Management, Manchester Metropolitan University, Manchester, UK, and

Olatunji David Adekoya

Royal Docks School of Business and Law, University of East London, London, UK

\begin{abstract}
Purpose - The COVID-19 pandemic has affected women in unique gender-specific ways, particularly their traditional status as home managers. This study aims to draw on the role theory to examine the impact of the COVID-19 pandemic on women's work-family balance during the lockdown.

Design/methodology/approach - The current COVID-19 pandemic, which has altered the ways in which we live and work, requires specific methodological tools to be understood. The authors, therefore, opted for an interpretive-constructivist and constructivist-phenomenologist approach. The dataset, thus, comprises of semi-structured interviews with 26 working women in the UK.

Findings - The findings illustrate how the COVID-19 lockdown has intensified British women's domestic workload and has, thus, caused unbridled role conflict, which has further been exacerbated by structural and interactional roles undertaken by women, especially during the lockdown. Remote working has contributed to women's role congestion and role conflict and poses severe challenges to role differentiation. Furthermore, we found that the lockdown has facilitated the rediscovery of family values and closeness, which is connected to the decline in juvenile delinquency and low crime rate that has resulted from the lockdown.

Originality/value - Through the lens of the role theory, this study concludes that the cohabitation of work and family duties within the domestic space undermines the ability to achieve work-family balance and role differentiation due to the occurrence of inter-role conflicts. This study enriches our understanding of the effect of remote working on female employees' work-family balance during the unprecedented COVID-19 pandemic lockdown.
\end{abstract}

Keywords Work-family balance, Women, Role theory, Gender role, Remote/virtual working, COVID-19 Paper type Research paper

\section{Introduction}

This article examines the impact of the COVID-19 pandemic on women's work-family balance (WFB). WFB is a much discussed and much sought after - but rarely claimed and achieved - state of being. Literally, WFB means cutting back on work to spend more time with one's family (Greenhaus et al., 2003). Despite the presumed virtues of WFB and researchers' call for organisations, families and individuals to recognise the importance of balancing work demands and family needs (Kreiner et al., 2009), many people (especially women) still struggle to achieve balance between these two important spheres of life. It has

(C) Toyin Ajibade Adisa, Opeoluwa Aiyenitaju and Olatunji David Adekoya. Published in Journal of Work-Applied Management. Published by Emerald Publishing Limited. This article is published under the Creative Commons Attribution (CC BY 4.0) licence. Anyone may reproduce, distribute, translate and create derivative works of this article (for both commercial and non-commercial purposes), subject to full attribution to the original publication and authors. The full terms of this licence may be seen at http:// creativecommons.org/licences/by/4.0/legalcode
Work-family balance

Received 31 July 2020 Revised 20 October 2020

16 November 2020

Accepted 27 December 2020 
JWAM

13,2

been observed that the $21^{\text {st }}$-century women from all walks of life want to have it all - a blissful family, a rewarding career and private space and time for themselves (Kashyap, 2018). However, working women experience greater difficulty than men in achieving WFB (Sundaresan, 2014). This perhaps is due to their social and cultural obligations as the primary caretakers of children, many times of elderly parents (especially in the global south), as well as work duties. The onset of COVID-19, however, has fundamentally changed the ways in which people live and work across the world. The world awoke to the reality of a new pneumonic disease known as COVID-19 in December 2019. Having spread across various countries, COVID-19 has proven itself a highly infectious disease that has led to the death of more than 42,000 people in the United Kingdom (UK) (Office for National Statistics, 2020).

As a result, governments across the world have implemented detailed but different plans and measures to stop the spread of the pandemic. The UK government, in March 2020, closed all schools, restaurants, pubs, indoor entertainment venues and leisure centres and imposed a lockdown on the whole population, banning all "non-essential" travel and contact with people outside one's home (The Health Protection Regulations, 2020). Virtual working has replaced the usual mode of working, and family life has also ceased to be "normal". Both work and life now take place in people's homes, which challenges the notion of work being confined to employment, remuneration and location. What are the implications of this phenomenon on working UK women? This article, through the lens of the role theory, investigates the impact of the coronavirus lockdown on British working women's WFB. This article advances the understanding of British working women's WFB in what is arguably the most turbulent time in our lifetimes and how women are able to manage their work and family roles to achieve balance. The article also highlights the practical implications. This article is structured as follows. The next section discusses the context of WFB and virtual working. This is followed by a discussion of the theoretical background of the study. Thereafter, we describe our research method. The results are then presented, followed by a discussion and conclusion.

\section{Virtual working}

In the past two decades, organisations have witnessed a transformation in the pattern of work and employment, particularly in the industrialised world, with the advent of advanced technology and the propagation of virtual organisations (Halford, 2005; Webster and Leung, 2017). A spatial reconfiguration process across organisations through the use of information and communication technologies (ICTs) has facilitated the possibilities of telecommuting and virtual work (Fenner and Renn, 2010). Initially, the use of ICT was primarily for supporting employees working remotely as a means of helping them, especially women, balance competing work demands and family responsibilities (Halford, 2005). However, the reorganisation of the workplace through continuous innovation and creativity within the high-tech industry has resulted in half-empty offices, as organisations' proclivity for virtual working has increased (Fogarty et al., 2011). Thus, workers are no longer restricted to the four walls of their office space; rather, they are moving work away from the traditional office space to other spaces, such as digital working hubs, coffee shops, shared working spaces or cyberspace (Webster and Randle, 2016). This has reduced face-to-face contact and has promoted the necessary flexibility for achieving WLB (Fenner and Renn, 2010). The range and usage of virtual work vary across countries and occupations. They primarily depend on the level of investment in advanced ICT, the expertise of users and the degree of managerial support (Kossek et al. 2014; Clarke and Holdsworth, 2017). Furthermore, the use of virtual working is contingent on the richness, time spent on and frequency of communication (Ferry et al., 2001; Webster et al., 2004). The onset of COVID-19 has replaced the traditional face-to-face mode of work with virtual working. This phenomenon continues to stimulate research and attention into how women navigate the unknown to achieve WFB. 


\section{Women and work-family balance}

The increasing participation of women in paid employment in recent decades has been construed as one of the main reasons for work-family conflict (WFC) (Greenhaus and Beutell, 1985; Maertz and Boyar, 2011). Many decades ago, women had the sole responsibility of childcare and domestic support for their partners, and they had a limited interest in paid employment (Rafnsdóttir and Heijstra, 2013). Unlike most men, women take on multiple roles (e.g. house chores and caring responsibilities) within the home, which affects their ability to achieve WFB (Grünberg and Matei, 2020). Furthermore, the gendered cultural norms and assumptions that inhibit the greater involvement of men in familial work have significant consequences for most working women (Allen and Hawkins, 1999; Evertsson, 2014). Seierstad and Kirton (2015) argue that it is very challenging for women to "have it all" - that is, to be committed to their careers, spouses and children. The under-representation of women in high-level positions within the work, social and political environments demonstrate the difficulties of combining multiple roles for women (Grzywacz and Carlson, 2007; PaustianUnderdahl et al., 2016).

Women in most industrialised countries that promote egalitarianism are presumed to achieve better WFB (Rafnsdóttir and Heijstra, 2013) than women in the global south, especially Africa (Adisa et al., 2019a). However, despite the egalitarian culture promoted in many developed nations, the traditional belief and cultural or religious segregation between men and women hamper their achievement of WFB (Seierstad and Kirton, 2015). Furthermore, the patriarchal hegemonic features prevalent in many societies empower men to dominate women both at work and home, affecting the general wellbeing of women (Gruber and Szołtysek, 2016). Similarly, Adisa et al. (2019a) suggest that strong patriarchal norms and proclivity trigger WLC for women, which may also result in reduced productivity and effectiveness, both at work and home.

Scholars aver that flexibility at work facilitates WFB (Blair-Loy, 2009) because employees (especially women) are given the autonomy to decide their working hours and the location where they carry out their work (Toffoletti and Starr, 2016). In addition, Johansson Sevä and Oun (2015) advocate self-employment (based on the assumption that it facilitates flexibility) as a strategy for managing the competing demands of work and family. By contrast, studies reveal that entrepreneurs find it difficult to separate the boundaries between work and family (Adisa et al., 2019b; Pareek and Bagrecha, 2017). This is due to the flexibility of being able to work everywhere that is associated with entrepreneurship, and entrepreneurs are accustomed to long working hours (Adisa et al., 2019b).

Women are more involved in the upbringing and development of their children than men. This is presumed to cause WFC for women. According to Leccardi (1996), women's time is controlled by emotions and affection, which sometimes results in them giving up work and devoting time to their familial duties. However, this can be challenging for single mothers with no available support for attending to family needs (Moilanen et al., 2019). Therefore, the patterns of work and devotion to career progression among women make it difficult for them to combine work and family responsibilities (Thornthwaite, 2004; Wayne et al., 2017).

More importantly, the extant research on the general experiences of working women in the UK and those from other regions (Africa, Asia and the Middle East) living in the UK remains a popular debate in the WFB discourse (Lewis et al., 2008). Working women in the UK, like in many other countries, are generally subjected to juggling work and familial responsibilities. Hence, for many women in the UK, part-time work is deemed appropriate as a strategy for combining work and family commitments (Lyonette, 2015), as women attempt to co-ordinate, manage, harmonise, synchronise and integrate their dual role as a worker and homemaker (Warren, 2004). In 2013, 40\% of the women in the UK were engaged in part-time employment, which has been attributed to their need to fulfil their familial duties (Devine and Foley, 2020). Although there has been an increasing number of part-time working British men, the increase

Work-family balance 
JWAM

13,2 is often due to their inability to gain full-time work and is usually not a voluntary action taken to increase their fulfilment of family commitments (Lyonette, 2015).

Furthermore, the UK ranks second in the world in how expensive childcare is, as families spend $35.7 \%$ of their pay on childcare (World Economic Forum, 2019). Women on a low income frequently reduce their working hours and engage in informal childcare provisions (grandparents or relatives) as a means of managing their work and family lives (Adisa et al., 2016). Although their workload often remains unchanged despite reducing their work hours (which simultaneously increases the completion time for their work), many women opt to devote more time to their family commitments than to work (Warren, 2004). Studies also aver that women working part-time are more likely to experience an increase in their childcare and domestic roles than men, as the remainder of the reduced work hours is expected to be transferred to their home duties (Warren and Lyonette, 2015).

Nevertheless, several measures have been initiated to facilitate WFB, especially among female employees. These measures have been put together primarily by organisations and governments to improve the quality of life of employees while simultaneously boosting organisational productivity (Brough and Kalliath, 2009; Grünberg and Matei, 2020). Some of these measures include changes to working hours and conditions, strategising management and leadership practices, creating a supportive organisational culture, promoting the use of technology-assisted tools and reward systems (Coronel et al., 2010; Maertz and Boyar, 2011). In particular, policies such as paid maternity leave, annual leave, adoption leave, telecommuting, compressed work hours, job sharing and annualised hours constitute some of the family-friendly policies and initiatives employed across diverse organisations to promote WFB (Rafnsdóttir and Heijstra, 2013; Grünberg and Matei, 2020). Women have also devised alternative ways of coping with their work demands and family responsibilities. Some employ domestic workers to care for the children and help with household chores (Adisa et al., 2016).

Despite the variety of policies that have been initiated with the goal of facilitating WFB, research has shown that women continue to experience WFC (Guillaume and Pochic, 2009). This could be due to men's insignificant contributions to home duties and childcare responsibilities (Milkie et al., 2010). Although WFB policies have been found to contribute to an increased intimacy between women and their children, as well as to their spouses or partners, the inadequate spousal support received by women increases their levels of WFC (Rottenberg, 2019). Craig and Sawrikar (2009) argue that mothers have high levels of stress and workloads regardless of their age of their children, as they remain dedicated to ensuring that their development and well-being are prioritised.

\section{Theoretical background}

This study is underpinned by the role theory. The role theory addresses the formation of social behaviour on the individual and collective levels (Turner, 2001). Conceptualising role at the individual level equates to the tendency for an individual to act and feel differently when they are placed in a different situation or position; likewise, different individuals tend to act identically in similar relationships (Dev and Olsen, 1989). At the collective level, organisations and societies function through the allocation of distinct roles to particular individuals. However, at both levels, role equates to a cluster of behaviours and attitudes with associated attributes upon which the assigned individuals are viewed as having acted consistently or inconsistently depending on their performance within the role (Mentz et al., 2019).

Furthermore, the role theory assumes two critical approaches - structural and interactional. On the one hand, the structural approach defines role as a set of expectations (internal and external) that guide an individual, on which they are judged or judge themselves based on their conformity to the expectations (Turner, 2001). On the other 
hand, the interactional approach defines role as a comprehensive pattern for behaviour and attitude associated with a particular identity or entity performed by different individuals (Turner, 2001). Although roles are regarded as sets of identity-related expectations that exist in various measures of substantiality and consistency, individuals behave as they perceive such related roles (Richards and Hemphill, 2017). In addition, besides the expectations of a particular role, roles are also dependent on the location where the role is enacted, the demands of the role, role consensus and the skills that are associated with the acceptance of the role (Dev and Olsen, 1989).

Role differentiation remains the most fundamental element underlying the role theory. Role differentiation requires the identification and separation of various actions and sentiments, which are combined into separate roles (Turner, 2001). Role differentiation is categorised based on role functionality, representationality and tenability. Role functionality refers to the division of tasks to achieve a collaborative goal. Functionality differentiates roles by the associated skills, knowledge and dispositions; the actual and potential existing traits or qualities; or the act of minimising the incompatibility of goals (Hindin, 2007). Role representationality considers the representation of the role and the consistency of the components associated with the image portrayed by the role (Mentz et al., 2019). For instance, the traditional role of a woman is an image of someone who performs domestic duties within the home. Hence, role representationality is an expression of both positive and negative values in human behaviour. Role tenability refers to the balance and nature of the costs and benefits of a particular role (Turner, 2001). Therefore, tenability has the potential to enhance role benefits or minimise costs. There is a relationship between power and tenability such that the desirability of a particular role depends on the level of power associated with the role (Turner, 2001). For example, the desire for men and women to attain a top position at work is often related to the level of power related to that position.

In addition, the role theory is based on two critical perspectives: WFC and role enhancement. According to Pedersen et al. (2009), gender roles in WFB are built on the assumption that work and family are two distinct spheres of an individual's life, and as such, men and women perform multiple roles that have positive and negative outcomes. The role theory suggests that both men and women undertake both natural and unnatural roles (Barnett and Gareis, 2006). For women, the natural role consists of the responsibilities of being wives and mothers, while the unnatural role is associated with being employees. Men, on the other hand, perform their natural role as breadwinners or employees, while their unnatural role is connected with their responsibilities as fathers and husbands (Barnett and Gareis, 2006).

The emergence of the concept of WFC was due to the drastic rise in the participation of women in the workforce (Maertz and Boyar, 2011). Inter-role conflicts have increased as women combine paid employment with their traditional/natural roles (Kanter, 1977). The WFC perspective is based on the underlying assumptions of the scarcity hypothesis, according to which it is presumed that an individual has limited resources (time, attention and energy) to allocate among the competing demands of work and family (Barnett et al., 1992). Therefore, expending more resources to one role may deprive other roles of necessary resources, leading to inter-role conflict (Grünberg and Matei, 2020). Specifically, women who engage in multiple roles may find it challenging to efficiently allocate resources to each role to achieve optimal satisfaction for all those involved (Thornthwaite, 2004). Fundamental to the WFC perspective is the issue of long working hours for women and their connection to negative outcomes, such as the depletion of energy, increased strain and incompatible behaviours associated with their performance in the family role (Barnett and Gareis, 2006).

By contrast, the role enhancement perspective disputes the assumption that an individual's energy is fixed or limited. Rather, it is considered an expandable quantity (Barnett and Gareis, 2006). Furthermore, the role enhancement perspective makes a distinction between role

Work-family balance 
JWAM

13,2

246

quantity and role quality. While role quantity relates to the number of roles undertaken by an individual and provides an explanation for WFC (Barnett and Gareis, 2006), role quality is associated with identity affirmation, whereby the individual (a woman) in a particular role (e.g. mother) gives the assurance of providing significant attention and dedication within the role (Pedersen et al., 2009). Furthermore, Barnett and Gareis (2006) point out that role quality is more subjective, i.e. regardless of the presence or absence of good working conditions, an employee may find such conditions as being either rewarding or problematic. Hence, role quality is deemed a stronger predictor of health and well-being than role quantity; for instance, women may feel psychologically fulfilled even when they work for long hours if they are satisfied with their jobs (Gareis et al., 2009).

Furthermore, the COVID-19 pandemic provides a context where it is crucial to examine the impact of multiple roles on women's WFB, especially during the lockdown. It is pertinent to understand the implications of COVID-19 on the natural and unnatural roles occupied by women. Recent research has shown that women continue to struggle with juggling work and family responsibilities even while they are working from home, which has resulted in increased stress levels and inter-role conflicts as the blurring of borders has intensified (Nash and Churchill, 2020; Bahn et al., 2020). Therefore, this study uses role theory to understand the impact of working from home due to the COVID-19 lockdown on women's work and family lives.

\section{Research methodology}

This study employs a qualitative research method - specifically, a narrative approach - to examine the implications of the COVID-19 pandemic on British women's WFB. The study draws on interpretive-constructivist and constructivist-phenomenologist traditions, which stress a person's lived experience (Saunders et al., 2009). The rationale for this choice of methodology is that it provides an appropriate framework for the development of an in-depth understanding of the research phenomenon (Chang et al., 2010; Cresswell, 2008) and leads to richly detailed narratives of the lived experiences of individuals (Saunders et al., 2009).

\section{Sampling and data collection}

Participants were recruited from the existing contacts of the researchers. The sampling later developed into snowballing. This was essential for the sample to be purposeful (Mason, 2002; Sparkes and Smith, 2014). Variation sampling was used, which made it possible for the researchers to holistically investigate the impact of the COVID-19 lockdown on the participants' WFB (Maykut and Morehouse, 1994).

Due to the present lockdown situation, the interviews took place online, and participants were asked the same questions at different times to reduce any chance of bias. All participants passed the eligibility criteria of being fully employed with familial responsibilities. Based on the European Foundation's (2005) approach to understanding quality of life, participants were asked to share their experience of the COVID-19 lockdown in relation to the quality of their work and family life. Specifically, the participants were asked the following research questions: (1) How would you describe your WFB during the COVID-19 lockdown? (2) What impacts has the COVID-19 lockdown had on your work and family life? A sample of 21 working women participated in semi-structured interviews. As mentioned, the present lockdown situation means that the interviews had to be conducted online via Microsoft Teams and Skype. The semi-structured nature of the interviews permitted flexibility (Saunders et al., 2009) and enabled us to gather specific and rich data that has been vital to the achievement of the research's aim and objectives (Bryman, 2012). It important to note that sample size is not a problem when using qualitative research methods (Bryman, 2012). What is important is data saturation 
(Patton, 2012), which informs us that we have reached a stage at which further interviews were not uncovering new themes (Saunders et al., 2009).

Using Microsoft Teams and Skype helped greatly to widen the range of our sampling, thus incorporating variety (women in different professions) in the research by allowing us to reach the participants in various parts of the country (UK) without any need for travel. The use of online technologies are becoming more prevalent as research aids, with the internet now providing "new horizons for researchers" (Illingworth, 2001; Lo Iacono et al., 2016). Microsoft Teams and Skype interviews allowed us to conveniently interact with the researchers involved, which helped us identify trends in the responses of the participants from different walks of life. Having understood the purpose of the study, the participants signed the necessary consent forms electronically. The interviews were conducted in English. Each semi-structured interview lasted between 60 and $90 \mathrm{~min}$ and were recorded. All of the participants have childcare responsibilities (see Table 1 for the demographic characteristics of the participants). Please note that we have used pseudonyms to represent the participants' names to fulfil the promise of confidentiality made to them.

To improve the reliability of the interviews and to ensure that no important themes had been left uncovered, a further "five confirmatory" interviews were conducted, so 26 interviews in total were carried out. The findings of the five additional interviews corroborated the themes found in the previous 21 interviews, and there were no new emerging themes. This meant that we achieved data saturation (Glaser and Strauss, 1967). We then manually transcribed the interviews verbatim for analysis.

\section{Data analysis}

After the transcription, we meticulously went back to the beginning of each recording and reviewed every word to ensure that the transcribed version of the interview exactly matched the recorded version. We then severally read through the transcripts to gain a holistic understanding of the interview discussions with the 26 participants. After a narrative summary of the interviews had been drafted, open coding (the identification of key points and objectives that seemed to be significant to the data) was carried out (Boeije, 2005). At this stage, we questioned the meanings of particular words or phrases and thought carefully about their meaning and interpretations (Corbin and Strauss, 2008). The researchers then grouped the first set of codes into categories according to their common codes. By combining codes that had similar underlying ideas, four dominant themes and eight sub-themes emerged (Table 2).

We did not impose coding categories a priori; rather, we remained open to new insights by allowing the categories to emerge from the data to not miss any important themes. We then marked the categories with different colours to facilitate data analysis, and a thematic map was drawn. The main categories were further fine-tuned by frequent comparisons until a representative overview was achieved. Due to the exploratory nature of this study, a datadriven thematic analysis was employed. The choice to apply thematic analysis was based on the guidance of Braun and Clarke (2006), and the steps in the data analysis were based on Corbin and Strauss's (2008) recommendations. Emerging themes from the data became the categories for analysis (prearranged enigmas were verified twice to ensure reliability), and investigator triangulation (Polit and Beck, 2004) was applied.

\section{Research findings}

Drawing on the role theory, our analysis revealed the accounts of the work- and familyrelated lived experiences of working British women during the coronavirus lockdown. The accounts indicate that the onset of the COVID-19 pandemic has reconfigured women's work and family lives. The data analysis reveals four major themes: an increased domestic workload, proliferation of role conflict, rediscovery of family values and closeness and 


\begin{tabular}{|c|c|c|c|c|c|c|c|}
\hline $\begin{array}{l}\text { JWAM } \\
13,2\end{array}$ & No & Pseudonyms & Gender & $\begin{array}{l}\text { Marital } \\
\text { status }\end{array}$ & $\begin{array}{l}\text { Number of } \\
\text { children }\end{array}$ & Positions & $\begin{array}{l}\text { Years of work } \\
\text { experience }\end{array}$ \\
\hline \multirow[b]{4}{*}{248} & 1 & Grace & Female & Married & 2 & University lecturer & 5 \\
\hline & 2 & Hope & Female & Married & 1 & $\begin{array}{l}\text { Administrator } \\
\text { (HRMC) }\end{array}$ & 6 \\
\hline & 3 & Comfort & Female & Single & 3 & Financial analyst & 4 \\
\hline & 4 & Beatrice & Female & Married & 2 & Project manager & 6 \\
\hline \multirow{22}{*}{$\begin{array}{l}\text { Table } 1 . \\
\text { Demographic } \\
\text { characteristics of } \\
\text { participants }\end{array}$} & 5 & Sophia & Female & Single & 2 & HR specialist & 3 \\
\hline & 6 & Emma & Female & Married & 2 & University lecturer & 2 \\
\hline & 7 & Olivia & Female & Divorced & 2 & HR manager & 12 \\
\hline & 8 & Elizabeth & Female & Married & 3 & Credit facility officer & 5 \\
\hline & 9 & Victoria & Female & Single & 1 & Auditor & 10 \\
\hline & 10 & Ava & Female & Married & 3 & Brand manager & 6 \\
\hline & 11 & Mia & Female & Married & 2 & University lecturer & 6 \\
\hline & 12 & Charlotte & Female & Single & 2 & Council officer & 3 \\
\hline & 13 & Amelia & Female & Single & 3 & Cyber analyst & 7 \\
\hline & 14 & Evelyn & Female & Married & 2 & Council officer & 4 \\
\hline & 15 & Abigail & Female & Married & 2 & Admin officer & 2 \\
\hline & 16 & Harper & Female & Married & 2 & School manager & 8 \\
\hline & 17 & Elena & Female & Single & 3 & Senior practice officer & 8 \\
\hline & 18 & Ella & Female & Single & 2 & University lecturer & 6 \\
\hline & 19 & Madison & Female & Married & 4 & Senior accountant & 10 \\
\hline & 20 & Chloe & Female & Divorced & 2 & $\begin{array}{l}\text { Marketing content } \\
\text { executive }\end{array}$ & 6 \\
\hline & 21 & Zoey & Female & Married & 1 & $\begin{array}{l}\text { Client service } \\
\text { supervisor }\end{array}$ & 8 \\
\hline & 22 & Zara & Female & Single & 2 & Council officer & 6 \\
\hline & 23 & Lilian & Female & Married & 1 & Council officer & 5 \\
\hline & 24 & Eleanor & Female & Married & 2 & Account manager & 7 \\
\hline & 25 & Natalie & Female & Married & 2 & $\begin{array}{l}\text { Account/marketing } \\
\text { officer }\end{array}$ & 4 \\
\hline & 26 & Lesley & Female & Single & 2 & University lecturer & 6 \\
\hline
\end{tabular}

reduced juvenile delinquency. We focus on these themes in our attempt to understand the impact of the COVID-19 lockdown on women's WFB. Our study suggests that the pandemic has reshaped women's WFB - at least for the time being, and potentially for the foreseeable future.

\section{Increased domestic workload}

An analysis of the participants' accounts of their work and family lives during the COVID-19 lockdown reveals that women have engaged more in domestic duties. With everyone confines to their home, women's traditional "home manager" duties have increased, which has affected the majority of the participants' WFB. The lockdown, for the majority of the participants, means that WFB is temporarily on hold. A participant commented:

There is nothing like WFB at the moment. My domestic work has drastically increased since the lockdown began in March. I have to care for everyone from morning till bedtime. It is very exhausting (Grace, University Lecturer).

Another participant said:

I can't wait to return to normal life. Life at the moment is really hectic, with three children to care for, and of course, my husband...I am in and out of the kitchen, cleaning up their mess everywhere...feeding the little one... and having to do laundry every now and then. it's crazy (Elizabeth, Credit Facility Officer). 


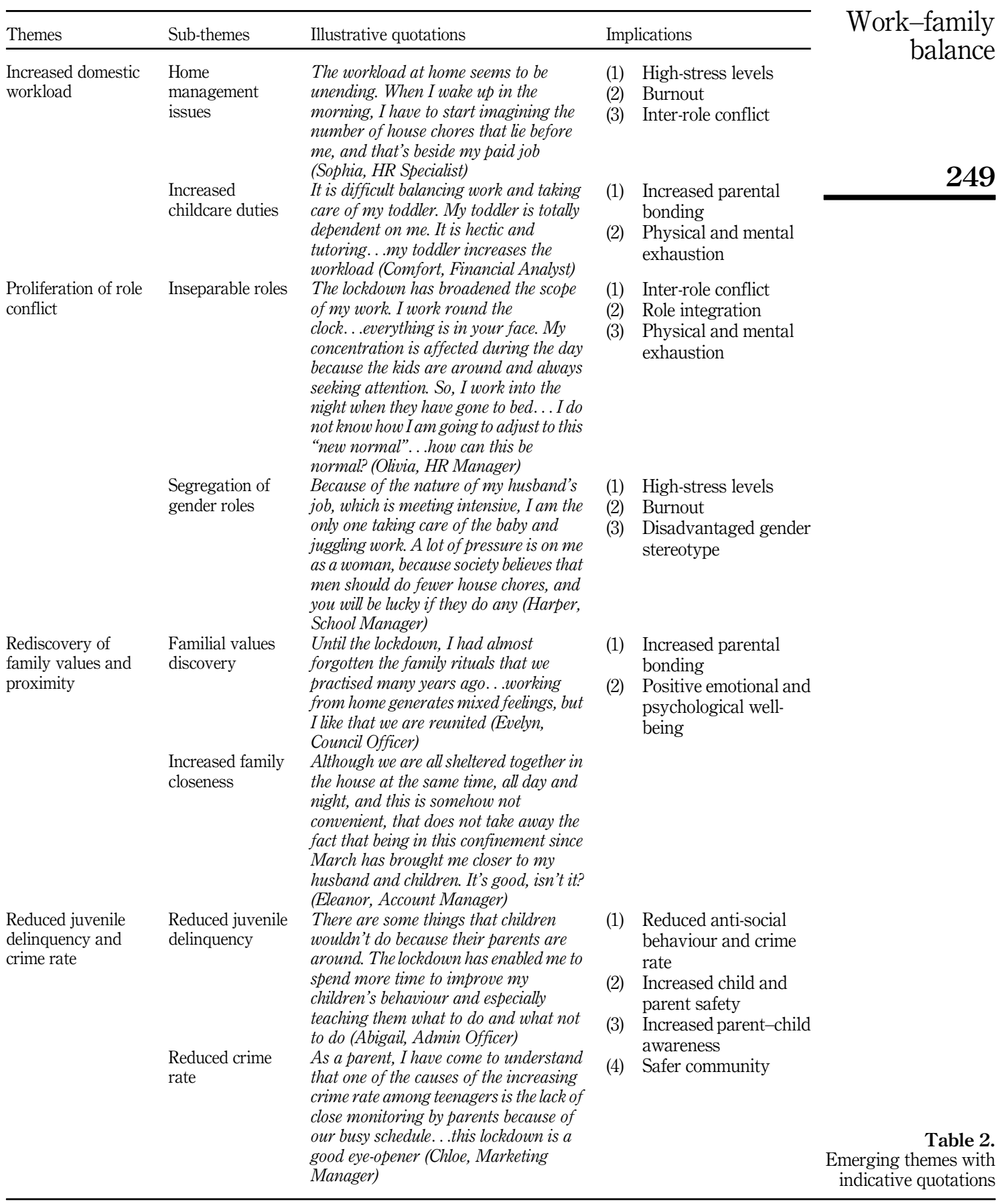


JWAM

13,2

The majority of the participants explained that the need to help their children with online schoolwork has added to their domestic duties. During the lockdown, women juggle their traditional domestic work with the children's schoolwork:

I have also taken up the role of an assistant teacher, sometimes a teacher. . .helping the children out with their school work. Getting them to concentrate is a herculean task, because they are not used to learning at home. They are used to learning at school and playing at home. . but now, they are doing the two at home. It is awkward and increases my workload (Elena, Assistant Audit Manager).

The participants indicated that child minders and carers are also affected by the lockdown, which has restricted their services. Furthermore, they pointed to the inadequate support they received from their spouses or partners regarding shared domestic duties as one of their difficulties in achieving WFB. One participant recounted her lived experience of the situation:

I am used to dropping off my kids to the child minder, who takes them to school in the morning and collect them in the evening. So, basically, I used to share the childcare duties with the child minder all of these have changed with the lockdown. . .the workload has increased. Having to support the kids with their online classes and the fact that my husband does very little domestic chores make my WFB miserable (Madison, Senior Accountant).

The accounts of these participants reveal that they are overwhelmed by their domestic work as a result of the COVID-19 lockdown. The increase in duties may have been manageable if their spouses or partners had been supportive by adequately helping with domestic chores.

\section{Proliferation of role conflict}

The participants reported an increase in role conflict as a result of the COVID-19 lockdown, which many of them described as a "rollercoaster". Their work and domestic roles significantly interfere with one another, thus causing tension and imbalance between the two. For example, a university lecturer stated that:

My work duties have suddenly been moved to the home, and my domestic duties have increased due to the COVID-19 lockdown. It is really difficult to separate the roles. . .for example, I will quickly leave a meeting (online) to attend to my children and then rush back to it; sometimes, I will be lost in the conversation because I have missed out on some minutes. . it's like a rollercoaster - crazy (Mia, University Lecturer).

Another participant commented on how she has struggled to separate her work and domestic roles during the lockdown:

I used to experience role conflict before the lockdown, but it has significantly worsened since the lockdown. My work and domestic duties have increased, and they are both happening in the same place [at home]. Sometimes, I lock myself up in a room to attend to my work duties, which my husband and children are really not happy about. . . and sometimes, I ignore work duties for a while to attend to my domestic duties. . . which also affects my work. I can't separate the roles. . .everything is happening at the same time (Hope, Administrator [Her Majesty's Revenue and Customs (HMRC)]).

The majority of the participants commented on the social construction of a woman's family role and the domestic division of labour as one of the reasons for the prevalent role conflicts during the COVID-19 lockdown. For example, a business analyst said:

As we know, women and men perform different familial and domestic roles. Even though we both foot the family bills, my husband doesn't engage in what are termed “women's duties", such as cooking; bathing and caring for the kids; cleaning the house. . . all of these are considered women's duties. Unfortunately, these duties and work responsibilities have all increased since the lockdown, and I have to attend to all of them. . .making WFB difficult for me (Amelia, Business Analyst). 
Another participant commented on her single status as a major factor contributing to her lack of WFB and role conflict proliferation. She commented:

I think being single worsens my work-family role issues. . .perhaps it would have been better if I was married or if I had a partner. At least my husband/partner would have eased my responsibilities by helping out with some familial duties. But I am a single mum with three children. I am all alone, manoeuvring between conflicting roles [work and family] with no one to help me (Elena, Assistant Audit Manager).

It is evident in the participants' comments that the increase in employees' work demands and their familial duties, as a result of the COVID-19 lockdown, has exacerbated their role conflict. The lockdown has meant that work and familial duties now take place at home, thus making separation of the roles difficult and enhancing the proliferation of role conflict.

\section{Rediscovery of family values and closeness}

Despite the downsides of the coronavirus lockdown, some participants highlighted that the lockdown has helped them rediscover great family values and has resulted in their becoming even closer to their families. We found that a majority of the participants found reconciliation in family values by spending time with their family during the lockdown. A woman with two children said:

I have always cherished family values, but I have come to appreciate them even more during this lockdown. I get to spend quality time with my husband and children (Natalie, Account/Marketing officer).

\section{Another participant mentioned:}

One thing that I am grateful for amid the lockdown is that my family was able to reconcile our values and beliefs that we once held many years ago. Praying together and having family meetings were our normal routines years back - before I got stuck in work. . .I take this pandemic occurrence as a real lesson (Elizabeth, Credit Facility Officer).

Furthermore, the ability to exercise micro-WFB activities among some of the participants engendered positive outcomes like increased family bonding. For instance, a participant commented on the opportunity of getting to know certain things about her children:

It is not all bad after all. It could sound stupid, but the lockdown has helped me discover certain things about my child. For example, I never knew that my son does not like banana and a particular brand of cereal - something that until now has only been known to his dad and childminder. Now I know that - and some other things around the house (Beatrice, Project Manager).

During the lockdown, some of the participants claimed that their families grew fonder of each other and more connected. The participants alluded to engaging in joint family activities (cycling, gardening and playing different games), which was inadequate before the lockdown. In addition, a participant told us how the COVID-19 lockdown helped her rekindle her love for her husband:

I have never in my life spent three weeks without a break with my husband. We have been together for more than eight weeks now - we watch TV together, eat meals together, and share stories...that has refreshed our relationship and rekindled our love. So, I will say the lockdown is good for family values and unity (Ava, Brand Manager).

Thus, we found that in the context of the COVID-19 pandemic, some participants expressed the joy of newfound family togetherness and love. Consistent with our findings, Stieger and Lewetz (2016) suggested that family closeness promotes basic values and engenders positive emotional and psychological well-being among families. Thus, the lack of parent-child
Work-family balance

\section{$-$}


JWAM

13,2

closeness generates an adverse effect on the emotional and psychological well-being of both the parent and child (Yahirun and Arenas, 2018).

\section{Reduced juvenile delinquency and crime rate}

Our findings have revealed that there has been a significant reduction in juvenile delinquency and other related anti-social behaviours among children. The participants unanimously believed that the lockdown reduced anti-social behaviour among children in their various neighbourhoods due to the increased parental supervision. The lockdown has meant that parents, especially women, are able to spend more time with their children, which resulted in the children's good behaviour. One participant commented:

There is relative peace in the neighbourhood. Before the lockdown, you would see the kids in their various groups fighting each other. Sometimes, they injured and even killed each other before the police arrived. . But now, kids are also confined to their homes, and their parents are watching and supervising them (Zoey, Client Service Supervisor).

Many parents do not know what their children do in their absence. The lockdown enabled them to find out a little more about their children and their hidden behaviour. A participant said:

I have a fourteen-year-old boy, whom I think is old enough to look after himself. I normally leave home before 7am and do not return until around 6:30pm, sometimes at $7 \mathrm{pm}$. Inever knew my son is in a gang that disturbs the neighbourhood. During this lockdown, I found out he had some strange attitudes, and a neighbour told me more about him (his attitude and group) and advised me to make more time for him. I have spent the last hundred days during the lockdown lecturing and counselling him. . .I think we are making progress. I will have to rethink my work patterns to make more time for him (Victoria, Auditor).

While many stories recounted by the participants reveal the impact of the COVID-19 lockdown on their children's attitudes and behaviours, which has resulted in a reduction in juvenile delinquency, a tendency of the lockdown to lower crime rate was likewise found in the participants' accounts, especially among those working in the local councils. For example, Zara commented:

This is the lowest crime rate that we have recorded in the last ten years. Since the lockdown, parents have been spending quality time with their children, and that has significantly lowered the crime rate (Zara, Council Officer).

Against this backdrop of a decreasing crime rate was the perception among the participants that if parents (especially mothers) would continue to create time to spend with their children, youth crime would eventually disappear. One participant said:

I work in the council, and the rate of crime has drastically reduced since the lockdown. I think this is down to mothers spending more time with their children. I think we can keep reducing the crime rate if we could get mothers to spend more time with their children (Lilian, Council Officer).

Given the participants' accounts of the impact of the COVID-19 lockdown on juvenile delinquency and the crime rate, this study suggests a rethink of how juvenile delinquency and youth crime are perceived and tackled. Our findings show the importance of women's time and counselling in reducing juvenile delinquency and crime rate. These findings are consistent with previous research, which has highlighted the importance of women in building a peaceful society (Porter, 2003).

\section{Discussion and conclusion}

This study examined the impact of COVID-19 lockdown on women's work and family lives. Our study has drawn on the role theory, considering the COVID-19 outbreak that has altered 
our modes of living and working, to understand how women manage their work and family roles to achieve WFB. As the COVID-19 pandemic continues to determine the momentum of work and family lives in the UK and across the globe, the work from home strategy and new roles undertaken by women at home continue to affect their WFB. The lockdown has meant that people are living and connecting in "social bubbles" and around their homes as opposed to wider social spaces once also known as "workplaces".

The aforementioned findings highlight the pressures that women have faced as a result of their increased domestic workload. Women have undertaken more domestic duties during the lockdown compared to the pre-COVID-19 period. According to Savage (2020), the COVID-19 situation has created significant frustration for women, as they have shouldered the bulk of domestic duties. The participants also undertake the new role of "assistant teacher" by helping their children with remote schoolwork. These phenomena have affected the majority of women and have resulted in their WFB temporarily being on hold. Research evidence that is consistent with these reported findings shows that parents, during the lockdown, find the workload and the job of supervising their children's home-schooling frustrating (Horton, 2020; Lyons, 2020). Furthermore, we argue that the structural role approach was dominant, given the set of defined expectations associated with being a mother and wife. These roles, also referred to as the natural roles of women (Barnett and Gareis, 2006), increased dramatically during the lockdown due to the COVID-19 measures. Furthermore, the natural role of a woman as a "caregiver or caretaker" supports the interactional role approach, which identifies the pattern of the roles played by women as a social role that is generally sustained through the behaviour and attitude elicited from such role. The increasing engagement of women in domestic work aligns with the notion of the role theory as a set of identity-related expectations (e.g. caregiving and house chores), which are measured by their substantiality and consistency (Richards and Hemphill, 2017).

Our study has highlighted the proliferation of role conflict among women as a result of the increase in their work and familial duties due to the COVID-19 lockdown. Their involvement in multiple roles at the same time and in the same place leaves their time and energy depleted, which are stressors for role conflict. Greenglass (2005) argued that an increase in familial expectations and duties often results in role conflict. There is an apparent contention between the participants' multiple roles - thus intensifying role pressures from work demands and family duties, which are mutually incompatible (Greenhaus and Beutell, 1985) - thereby causing WFC. We argue that the inter-role conflict, which is due to the cohabitation of work and family duties within the domestic space, engenders significant challenges to differentiation between roles. As the participants experienced increasing role overlap, role differentiation proved to be difficult to achieve and affected their performance both at work and home. In addition, the desire to successfully navigate their work and familial duties was a futile exercise for a majority of the women, leading to severe role conflict and tension between roles. Furthermore, the integration of the work and family roles affected the representationality thereof, as many of the women found it difficult to carry out their responsibilities within the formerly distinct roles. The ubiquitous experience resulting from the attempt to fulfil their role expectations (both at work and home) within the same space, and the increase in role demand exacerbated the occurrence of WFC among the women.

Our findings, notwithstanding the downsides of the COVID-19 pandemic lockdown strategy, also suggest that a positive relationship exists between the increased work and family duties, role conflict, family values and closeness and reduced juvenile delinquency and crime rate. For some participants, being sequestered at home has rejuvenated their relationships with their spouses, has brought families together and has even resulted in increased parent-child closeness - something that had hitherto been affected by the competing demands of paid work and other non-work commitments. In addition, the findings have revealed the existence of role tenability despite the increasing demands of work and
Work-family balance 
JWAM

13,2 family roles. Significantly, the participants were able to become closer to their children and spouses and increase their caregiving role, despite its interference with work activities. Using the skills linked with being a mother and wife, they were able to stimulate family closeness to promote a healthy family life. As role tenability suggests, there were costs and benefits for the participants as they faced increasing role demands (costs), but they also gained some level of family togetherness (benefits). Furthermore, the tenability of women's roles provides some benefits to the community. For instance, although the costs of performing their caregiving role increased due to the increasing work demands while working from home, the benefits to society (reduced anti-social behaviour) seem to have generated a balance and have positively impacted society.

Our findings also provide evidence of role enhancement. The energy exerted by the women was used in an expandable quantity rather than being fixed or limited (Barnett and Gareis, 2006). For instance, performing multiple roles (through multitasking) engendered a sense of satisfaction for the women, particularly concerning the positive outcomes from being close to their family members and reigniting family values. For these women, the increase in familial role quality and quantity was deemed important, despite the absence of good working conditions exacerbated by increased role demands and expectations.

We also found that role representationality is an expression of both positive and negative values in human behaviour. For instance, just as a cleric is imaged as an embodiment of godliness, the image of a woman is that of her social role of childrearing (Stenius et al., 2005). In consonance with the study of Pinquart (2017), our findings suggest that the consistency in parental supervision because of the mothers' increased presence at home tends to have contributed to a reduction in juvenile delinquency and crime rate across communities, as explained by the council officers. Therefore, Turner (2001) argues that the deep attachment to role identity because of its ability to recur and create intimate social relationships that are inseparable from a person (e.g. a woman) could sometimes create a system that offers significant reward to the role incumbent (e.g. a woman). Thus, our findings report mixed feelings - the participants complained of increasing domestic workload and the proliferation of role conflict, but they lauded the benefits of increased family values and togetherness as well as the reduced juvenile delinquency and crime rate.

\section{Contributions, implications, limitations and directions for future research}

Our study contributes to the research on this topic through its theoretical and practical implications. From the theoretical perspective, our findings add to the discourse on WFB by substantiating the foregoing evidence that WFB is dependent on demands from both work and family, role expectations and the amount of resources (time, attention and energy) expended to fulfil work and family responsibilities (Barnett et al., 1992; Greenhaus et al., 2003). We aver that the excessive allocation of resources to one role at the detriment of the other may lead to inter-role conflict and may result in WFC, as revealed within our study context. In particular, through the lens of the role theory, we explored the case of working women in the UK and the impact of their roles on their WFB. We found that the structural and interactional role of women continues to affect their WFB positively and negatively, as a result of the expectations and social identity associated with being a woman.

Moreover, a significant contribution from this study relates to the lived experiences of working British women in navigating their work and familial obligations during the novel COVID-19 pandemic. We argue that the cohabitation of work and family duties within the domestic space undermines the ability to achieve WFB and role differentiation due to the occurrence of inter-role conflicts. The overlapping roles, which are the result of long working hours and an increasing domestic workload, challenged the functional role of the majority of women, while it also affected the representationality of the role and led to tensions within the 
role - even WFC. However, the ability of the majority of women to multitask (especially during the pandemic) supports role enhancement and tenability, and it yields positive outcomes for managing work and family life, regardless of the intensity of work and family demands.

From a practical perspective, WFC is likely to persistently constitute a part of womanhood if policy measures are not reconsidered for mitigating the dysfunctional interferences between work and family life (Grünberg and Matei, 2020). Furthermore, with the profound changes in the ways in which we live and work presently taking place across the globe, the rediscovery of family love and values will help in terms of work and family synthesis, and this will ameliorate the effect of the role conflict caused by the COVID-19 pandemic. An intriguing finding of this study is that there has been a significant reduction in juvenile delinquency and other related anti-social behaviours during the lockdown. One plausible explanation for this is that parents, especially women, are spending more time with their children at home, thus preventing them from bad company. Based on this finding, the government could rethink their strategies to reduce the current rates of hooliganism and crime. Reducing women's working days and working hours, without a backlash to their career advancement, could be one way to go.

While our study advances understanding of women's WFB, particularly during the COVID-19 lockdown, it also has some limitations, which in turn open up opportunities for future research. First, our study is based on only 26 interviews with female participants; we, therefore, cannot generalise our results to other research contexts like, for example, Africa, Asia and the Middle east. However, based on Malterud et al.'s (2016) argument about information power (the more information the sample holds relevant for the actual study, the lower the number of participants that is required) and saturation, we believe this was a sufficient sample size. Furthermore, the use of Microsoft Teams and Skype as a medium for conductive the interviews for this study had limitations - there was limited rapport, non-verbal cues and ethics, which would have been eradicated in face-to-face interviews. However, the methods opened up new possibilities by allowing researchers to reach participants, regardless of their geographical locations in a time-efficient and financially affordable manner (Lo Iacono et al., 2016). We contend that these limitations provide stimulus for future research. For instance, future research could consider investigating the WFB experiences of married and single-parent women to find out if there are any significant distinctions. Future research can also explore the impact of the COVID-19 pandemic on WFB, specifically for women working in the informal sector and women-led enterprises. In conclusion, we hope our study not only opens up exciting new research opportunities in the patterns of women's work and family life and how they are able to reconcile these incompatible roles, as we navigate the evolving work and family environment.

\section{References}

Adisa, T.A., Gbadamosi, G. and Osabutey, E.L.C. (2016), "Work-family balance: a case analysis of coping strategies adopted by Nigerian and British working mothers", Gender in Management: An International Journal, Vol. 31 No. 7, pp. 414-433.

Adisa, T.A., Abdulraheem, I. and Isiaka, S.B. (2019a), "Patriarchal hegemony: investigating the impact of patriarchy on women's work-life balance", Gender in Management: An International Journal, Vol. 34 No. 1, pp. 19-33.

Adisa, T.A., Gbadamosi, G., Mordi, T. and Mordi, C. (2019b), "In search of perfect boundaries? Entrepreneurs' work-life balance”, Personnel Review, Vol. 48 No. 6, pp. 1634-1651.

Allen, S.M. and Hawkins, A.J. (1999), "Maternal gatekeeping: mothers' beliefs and behaviours that inhibit greater father involvement in family work", Journal of Marriage and Family, Vol. 61 No. 1, pp. 199-212.
Work-family balance 
JWAM

13,2

Bahn, K., Cohen, J. and Rodgers, V. (2020), "Feminist perspective on COVID-19 and the value of care work globally", Gender, Work and Organization, pp. 1-5, available at: https:/onlinelibrary.wiley. com/doi/epdf/10.1111/gwao.12459 (accessed 25th July 2020).

Barnett, R.C. and Gareis, K.C. (2006), "Role theory perspectives on work and family", in PittCatsouphes, M., Kossek, E.E. and Sweet, S. (Eds), The Work and Family Handbook: MultiDisciplinary Perspectives, Methods, and Approaches, Lawrence Erlbaum Associates Publishers, pp. 209-221.

Barnett, R.C., Marshall, N.L. and Singer, J.D. (1992), "Job experiences over time, multiple roles, and women's mental health: a longitudinal study", Journal of Personality and Social Psychology, Vol. 64 No. 4, pp. 634-644.

Blair-Loy, M. (2009), "Work without end? Scheduling flexibility and work-to-family conflict among stockbrokers", Work and Occupations, Vol. 36 No. 4, pp. 279-317.

Boeije, H. (2005), 'Analysing in Qualitative research.' Thinking and Acting, Boom Onderwijs, Amsterdam.

Braun, V. and Clarke, V. (2006), "Using thematic analysis in psychology", Qualitative Research in Psychology, Vol. 3 No. 2, pp. 77-101.

Brough, P. and Kalliath, T. (2009), "Work-family balance: theoretical and empirical advancements", Journal of Organizational Behavior, Vol. 30, pp. 581-585.

Bryman, A. (2012), Social Research Methods, 4th edn, Oxford University Press, New York, NY.

Chang, A., McDonald, P. and Burton, P. (2010), "Methodological choices in work-life balance research 1987 to 2006: a critical review”, International Journal of Human Resource Management, Vol. 21 No. 13, pp. 2381-2413.

Clarke, S. and Holdsworth, L. (2017), Flexibility in The Workplace: Implications of Flexible Work Arrangements for Individuals, Teams and Organisations Advisory, Conciliation and Arbitration Service - ACAS, Britain.

Corbin, J. and Strauss, A. (2008), Basics of Qualitative Research: Techniques and Procedures for Developing Grounded Theory, Sage, Thousand Oaks, CA.

Coronel, J.M., Moreno, E. and Carrasco, M.J. (2010), "Work-family conflicts and the organizational work culture as barriers to women educational managers", Gender, Work and Organization, Vol. 17 No. 2, pp. 219-239.

Craig, L. and Sawrikar, P. (2009), "Work and Family: how does the (gender) balance change as children grow?", Gender, Work and Organization, Vol. 16 No. 6, pp. 684-709.

Cresswell, J.W. (2008), Research Design, Qualitative and Mixed Methods Approaches, Sage, Thousand Oaks, CA.

Dev, C.S. and Olsen, M.D. (1989), "Applying role theory in developing a framework for the management of customer interactions in hospitality businesses", International Journal of Hospitality Management, Vol. 8 No. 1, pp. 19-33.

Devine, B.F. and Foley, M. (2020), Women and the Economy, House of Commons Library, available at: https://researchbriefings.files.parliament.uk/documents/SN06838/SN06838.pdf.

European Foundation (2005), "Work-related stress", available at: https://www.eurofound.europa.eu/ publications/article/2005/work-related-stress (accessed 13 July 2020).

Evertsson, M. (2014), "Gender ideology and the sharing of housework and child care in Sweden", Journal of Family Issues, Vol. 35 No. 7, pp. 929-949.

Fenner, G.H. and Renn, R.W. (2010), "Technology assisted supplemental work and work-to-family conflict: the role of instrumentality beliefs, organizational expectations and time management", Human Relations, Vol. 63 No. 1, pp. 63-82.

Ferry, D.L., Kydd, C.T. and Sawyer, J.E. (2001), "Measuring facets of media richness", Journal of Computer Information Systems, Vol. 41 No. 4, pp. 69-78. 
Fogarty, H., Scott, P. and Williams, S. (2011), "The half-empty office: dilemmas in managing locational flexibility", New Technology, Work and Employment, Vol. 26 No. 3, pp. 183-195.

Gareis, K.C., Barnett, R.C., Ertel, K.A. and Berkman, L.F. (2009), "Work-family enrichment and conflict: additive effects, buffering, or balance?”, Journal of Marriage and Family, Vol. 71, pp. 696-707.

Glaser, B.G. and Strauss, A.L. (1967), The Discovery of Grounded Theory, Aldine de Gruyter, New York, NY.

Greenglass, E.R. (2005), "Proactive coping, resources and burnout: implications for occupational stress", in Antoniou, A.-S.G. and Cooper, C.L. (Eds), New Horizons in Management. Research Companion to Organizational Health Psychology, Edward Elgar Publishing, pp. 503-515.

Greenhaus, J.H. and Beutell, N.J. (1985), "Sources and conflict between work and family roles", Academy of Management Review, Vol. 10, pp. 76-88.

Greenhaus, J.H., Collins, K.M. and Shaw, J.D. (2003), "The relation between work-family balance and quality of life", Journal of Vocational Behavior, Vol. 63, pp. 510-531.

Grünberg, L. and Matei, Ş. (2020), "Why the paradigm of work-family conflict is no longer sustainable: towards more empowering social imaginaries to understand women's identities", Gender, Work and Organization, Vol. 27, pp. 289-309.

Gruber, S. and Szołtysek, M. (2016), "The patriarchy index: a comparative study of power relations across historical Europe", The History of the Family, Vol. 21 No. 2, pp. 133-174.

Grzywacz, J.G. and Carlson, D.S. (2007), "Conceptualizing work-family balance: implications for practice and research", Advances in Developing Human Resources, Vol. 9, pp. 455-471.

Guillaume, C. and Pochic, S. (2009), "What would you sacrifice? Access to top management and the work-life balance", Gender, Work and Organization, Vol. 16 No. 1, pp. 14-36.

Halford, S. (2005), "Hybrid workspace: Re-spatialisations of work, organisation and management", New Technology, Work and Employment, Vol. 20 No. 1, pp. 19-33.

Hindin, M.J. (2007), "Role theory” in Ritzer, G. (Ed.), The Blackwell Encyclopedia of Sociology. doi:10.1002/ 9781405165518.wbeosr078.

Horton, H. (2020), "Parents struggle with home-schooling as they complain 'maths has changed' on first day of closures", The Telegraph, available at: https:/www.telegraph.co.uk/news/2020/03/23/ parents-struggle-homeschooling-complain-maths-has-changed-first/ (accessed 10th July 2020).

Illgworth, N. (2001), "The internet matters: exploring the use of the internet as a research tool", Sociological Research Online, Vol. 6 No. 2, pp. 79-90.

Johansson Sevä, I. and Öun, I. (2015), "Self-employment as a strategy for dealing with the competing demands of work and family? The importance of family/lifestyle motives", Gender, Work and Organization, Vol. 22 No. 3, pp. 256-272.

Kanter, R. (1977), Men and Women of the Corporation, Basic Books, New York, NY.

Kashyap, V. (2018), “A working woman's guide to maintain work-life balance. thrive global”, available at: https://medium.com/thrive-global/a-working-womans-guide-to-maintain-work-life-balance27aa63e2f743 (accessed 25th June 2020).

Kossek, E.E., Hammer, L.B., Thompson, R.J. and Burke, L.B. (2014), Leveraging Workplace Flexibility: Fostering Engagement and Productivity, SHRM Foundation, Alexandria, VA.

Kreiner, G.E., Hollensbe, E.C. and Sheep, M.L. (2009), "Balancing borders and bridges: negotiating the work-home interface via boundary work tactics", Academy of Management Journal, Vol. 52 No. 4, pp. 704-730.

Leccardi, C. (1996), "Rethinking social time: feminist perspectives", Time and Society, Vol. 5 No. 5, pp. $169-86$.

Lewis, J., Campbell, M. and Huerta, C. (2008), "Patterns of paid and unpaid work in Western Europe: gender, commodification, preferences and the implications for policy", Journal of European Social Policy, Vol. 18, pp. 21-37.
Work-family balance

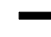


JWAM

13,2
Lo Iacono, V., Symonds, P. and Brown, D. (2016), "Skype as a tool for qualitative research interviews", Sociological Research Online, Vol. 21, pp. 12-36.

Lyon, K. (2020), “It's impossible': mother of four's tirade about remote schooling. The Guardian”, available at: https:/www.theguardian.com/world/2020/mar/20/coronavirus-impossible-mothertirade-remote-schooling (accessed 10th July 2020).

Lyonette, C. (2015), "Part-time work, work-life balance and gender equality", Journal of Social Welfare and Family Law, Vol. 37 No. 3, pp. 321-333.

Maertz, C.R. and Boyar, S.L. (2011), "Work-family conflict, enrichment, and balance under 'levels' and 'episodes' approaches", Journal of Management, Vol. 37 No. 1, pp. 68-98.

Malterud, K., Siersma, V.D. and Guassora, A.D. (2016), "Sample size in qualitative interview studies: guided by information power", Qualitative Health Research, Vol. 26 No. 13, pp. 1753-1760.

Mason, J. (2002), Qualitative Researching, 2nd ed., Sage, London.

Maykut, P.S. and Morehouse, R.E. (1994), Beginning Qualitative Research: A Philosophic and Practical Guide, Falmer Press, London.

Mentz, J.C., Schoeman, M.A. and Loock, M. (2019), "The roles, behaviors and expectations of the participants in the development of student graduateness", Innovative Technologies and Learning, Vol. 47, pp. 435-445.

Milkie, M.A., Kendig, S.M., Nomaguchi, K.M. and Denny, K.E. (2010), "Time with children, children's well-being, and work-family balance among employed parents", Journal of Marriage and Family, Vol. 72 No. 5, pp. 1329-1343.

Moilanen, S., Aunola, K., May, V., Sevón, E. and Laakso, M.-L. (2019), “Nonstandard work hours and single versus coupled mothers' work-to-family conflict”, Family Relations, Vol. 68 No. 2, pp. 213-231.

Nash, M. and Churchill, B. (2020), "Caring during COVID-19: a gendered analysis of Australian university responses to managing remote working and caring responsibilities", Gender, Work and Organization, pp. 1-14, doi: 10.1111/gwao.12484.

Office of National Statistics (2020), "All data related to coronavirus (COVID-19)", available at: https:// www.ons.gov.uk/peoplepopulationandcommunity/healthandsocialcare/conditionsanddiseases/ datalist (accessed 1st July 2020).

Pareek, P. and Bagrecha, C. (2017), "A thematic analysis of the challenges and work-life balance of women entrepreneurs working in small-scale industries", Vision: The Journal of Business Perspective, Vol. 21 No. 4, pp. 461-472.

Patton, M.Q. (2012), Qualitative Research and Evaluation Methods, Sage, London.

Paustian-Underdahl, S.C., Halbesleben, J.R.B., Carlson, D.S. and Kacmar, K.M. (2016), “The work-family interface and promotability: boundary integration as a double-edged sword", Journal of Management, Vol. 42 No. 4, pp. 960-981.

Pedersen, D.E., MinNotte, K.L., Kiger, G. and Mannon, S.E. (2009), "Workplace policy and environment, family role quality, and positive family-to-work spillover", Journal of Family and Economic Issues, Vol. 30 No. 80, pp. 80-89.

Pinquart, M. (2017), "Associations of parenting dimensions and styles with externalizing problems of children and adolescents: an updated meta-analysis", Developmental Psychology, Vol. 53 No. 5, pp. 873-932.

Polit, D.F. and Beck, C.T. (2004), Nursing Research. Principles and Methods, Lippincott Williams and Wilkins, Philadelphia, PA.

Porter, E. (2003), "Women: political decision-making and peace building”, Global Change, Peace and Security, Vol. 15 No. 3, pp. 245-262.

Rafnsdóttir, G.L. and Heijstra, T.M. (2013), "Balancing work-family life in academia: the power of time", Gender, Work and Organization, Vol. 20 No. 3, pp. 283-296. 
Richards, K.A.R. and Hemphill, M.A. (2017), "Using role theory to understand the experiences of physical education teachers: toward role socialization theory", in Richards, K.A.R. and Gaudreault, K.L. (Eds), Teacher Socialization in Physical Education: New Perspectives, Taylor \& Francis, New York, NY, pp. 147-161.

Rottenberg, C. (2019), "Women who work: the limits of the neoliberal feminist paradigm", Gender, Work and Organization, Vol. 26 No. 8, pp. 1073-1082.

Saunders, M.N.K., Thornhill, A. and Lewis, P. (2009), Research Methods for Business Students, 5th edition, Prentice Hall UK, London.

Savage, M. (2020), "How Covid-19 is changing women's lives. BBC work-life", available at: https:// www.bbc.com/worklife/article/20200630-how-covid-19-is-changing-womens-lives (accessed 13th July 2020).

Seierstad, C. and Kirton, G. (2015), "Having it all? Women in high commitment careers and work-life balance in Norway", Gender, Work and Organization, Vol. 22 No. 4, pp. 390-404.

Sparkes, A.C. and Smith, B. (2014), Qualitative Research Methods in Sport, Exercise and Health: From Process to Product, Routledge, London.

Stenius, V.M.K., Veysey, B.M., Hamilton, Z.M.A. and Andersen, R.M.S. (2005), "Social roles in women's lives", The Journal of Behavioral Health Services and Research, Vol. 32, pp. 182-198.

Stieger, S. and Lewetz, D. (2016), "Parent-child proximity and personality: basic human values and moving distance", BMC Psychology, Vol. 4 No. 26, pp. 1-12.

Sundaresan, S. (2014), "Work-life balance - implications for working women", International Journal Sustainable Development, Vol. 7 No. 7, pp. 93-102.

The Health Protection (Coronavirus, Business Closure) (Wales) Regulations (2020), available at: https://www.legislation.gov.uk (accessed 11 May 2020).

Thornthwaite, L. (2004), "Working time and work-family balance: a review of employees' preferences", Asia Pacific Journal of Human Resources, Vol. 42 No. 2, pp. 166-184.

Toffoletti, K. and Starr, K. (2016), "Women academics and work-life balance: gendered discourses of work and care", Gender, Work and Organization, Vol. 23 No. 5, pp. 489-504.

Turner, R.H. (2001), "Role theory", in Turner, J.H. (Ed.), Handbook of Sociological Theory. Handbooks of Sociology and Social Research, Springer, Boston, MA. doi: 10.1007/0-387-36274-6_12.

Warren, T. (2004), "Working part-time: achieving a successful 'work-life' balance?”, The British Journal of Sociology, Vol. 55, pp. 99-122.

Warren, T. and Lyonette, C. (2015), "The quality of part-time work", in Felstead, A., Gallie, D., Green, F. and Ananc, H. (Eds), Unequal Britain at Work, in Press, Oxford University Press, Oxford.

Wayne, J.H., Butts, M.M., Casper, W.J. and Allen, T.D. (2017), "In search of balance: a conceptual and empirical integration of multiple meanings of work-family balance", Personnel Psychology, Vol. 70 No. 1, pp. 167-210.

Webster, J. and Leung, W.F. (2017), "Introduction: creativity, knowledge and innovation in virtual work", New Technology, Work and Employment, Vol. 32 No. 1, pp. 1-11.

Webster, J. and Randle, K. (eds) (2016), Virtual Workers and the Global Labour Market, Palgrave Macmillan, London.

Webster, M., Sugden, D.M. and Tayles, M.E. (2004), "The measurement of manufacturing virtuality", International Journal of Operations and Production Management, Vol. 24 No. 7, pp. 721-742.

World Economic Forum (2019), "These countries have the most expensive childcare", available at: https://www.weforum.org/agenda/2019/04/these-countries-have-the-most-expensivechildcare/.

Yahirun, J.J. and Arenas, E. (2018), "Offspring migration and parents' emotional and psychological well-being in Mexico", Journal of Marriage and Family, Vol. 80 No. 4, pp. 975-991.

Work-family balance 
JWAM

13,2

\section{Further reading}

Lo, K. and Lamm, F. (2005), "Occupational stress in the hospitality industry - an employment relations perspective", New Zealand Journal of Employment Relations, Vol. 30 No. 1, pp. 23-48.

\section{Corresponding author}

Toyin Ajibade Adisa can be contacted at: t.adisa@uel.ac.uk

For instructions on how to order reprints of this article, please visit our website: www.emeraldgrouppublishing.com/licensing/reprints.htm Or contact us for further details: permissions@emeraldinsight.com 